\title{
Sciendo
}

\author{
Research Article \\ (c) 2018 Georgios Baltos and Carlotta Alpigiano. \\ This is an open access article licensed under the Creative Commons \\ Attribution-NonCommercial-NoDerivs License \\ (http://creativecommons.org/licenses/by-nc-nd/3.0/).
}

\section{From Audit-Phobia to Shared Governance Philosophies: Librarians Meet Auditors at the European University Institute ${ }^{1}$}

Georgios Baltos

Internal Audit Office,

European University Institute

\section{Carlotta Alpigiano}

Library,

European University Institute

Doi: 10.2478/jesr-2018-0035

\section{Abstract}

Libraries are rightfully recognized as the heart of academic institutions. However, they are not standalone, but interconnected with all other players within the same organisational universe: academia, administration, stakeholders, internal and external competitors and co-operators. Internal auditors' role is to promote quality standards along with a "continuous improvement" culture that includes efficiency, accountability and performance excellence at institutional level. Librarians have a long tradition of performance indicators' collection and evaluation. The crossroad where librarians and auditors meet each other is represented by an integrated methodology which links objectives, risks, performances and controls, harmonising them within the institutional context. The case of such a collaboration at European University Institute (EUI) is a noteworthy example.

Keywords: Corporate governance, libraries interoperability, risk-based auditing, objectives, performance self-assessment, administrative synergies

\section{Introduction}

Libraries are rightfully recognized as the heart of academic institutions. However, they are not standalone, they are instead interconnected with numerable parts and players within the same organisational universe, such as academia, the administration, a network of stakeholders, internal and external competitors and co-operators, whose interests and objectives should be taken into consideration by the Library management. New areas of libraries' interest (repositories, open access and open data, e-learning, support for scholarly publishing) imply collaboration with other services within the university. Librarians face micro- and macro-management challenges never experienced before.

Therefore, librarians have already "opened" their minds to the latest evolution of management best practices, where they are sharing risk-based and governance concepts and methodologies. The professionals who are also interested in the Libraries' efficiency, accountability and performance excellence are the internal auditors, in the sense that their mission is the promotion of quality standards along with the cultivation of a "continuous improvement" culture (Russell and Divisio, 2012). These "next-door neighbours" are also moving forward from their traditional, usually

${ }^{1}$ This paper was originally presented at the Qualitative and Quantitative Methods in Libraries - QQML 2017 Conference, 23-26 May 2017, Limerick, Ireland. 
considered supressing, assurance services to consulting engagements, offering advisory and insight towards a multi-faceted management success.

This paper discusses a roadmap as well as the pre-requisites for the recommended interoperability between Libraries and Auditing, emphasising the auditors' willingness to respect the Libraries' uniqueness, enhancing as much as possible the librarians' capabilities to self-assess their prospects and opportunities, averting threats and weaknesses. The crossroad where librarians and auditors meet is based upon an integrated methodology linking objectives, risks, performance indicators (PIs) and controls, customized for libraries' administrative and operational needs. The auditors are called upon to avoid harshly pointing the finger at the managers for any erroneous issues, but rather to provide their constructive consulting and know-how on a systematic selfassessment and timely prevention of managerial irregularities.

\section{Libraries and Auditing on an Evolutionary Trajectory}

Over the last decades the advances of knowledge, industries and technologies resulted in exponentially dynamic societal changes that consequently created core opportunities for progress in the future. The convergence of numerous scientific disciplines with several professional practices is taking place via escalating and transformative interactions, applying dramatic impact on the majority of modern communities and domains of human activity. On the other hand, evolution control and management of change are difficult for many professionals as long as they usually alternate habits and/or cause job losses, mobility and retraining needs (Meredith, 2009).

Although humanity has a long way to walk towards mutual compatibility, synergism, and integration, there is a common request through this dynamic evolution process for the creation of added quality value and shared goals of efficiency and effectiveness (Roco and Bainbridge, 2013). For example, we have already witnessed a long-term evolution of the schooling systems shifting from teacher-centric to student-centric ones (Hoidn, 2016). The whole world experiences the move from the traditional and heavily disciplined training courses into the "age of mobilism", where probably every student will shortly be using her/his own mobile computing device, processing the highest flow of information any education system ever tackled and utilised before (Norris and Soloway, 2011).

In another example, quality management has been transformed from compliance driven to culturally driven as well as from final products' inspection to the assurance that specifications and standards are respected in advance, in order to prevent manufacturing deficiencies and services discrepancies (Baltos and Vidakis, 2014). Public and private sectors have encouraged process analyses and evaluation, while management's awareness level for quality needs has been raised by the evolution of business services towards full customer satisfaction (Leek, 1987). In a similar way, libraries adapt to changes related to users' needs and expectations, technology, and funding.

The management of such revolutionary changes can be outlined in the transitions from print to online collections, from ownership to access, from in-site services to distributed services, from spaces devoted to collections to spaces dedicated to users, from "outside-in resources" to "insideout" resources (Dempsey, 2017). The auditors share the same existential wonders, thus they also follow, through their global associations, a sharp evolutionary trajectory, although carrying an additional responsibility in that they are called to evaluate and contribute in a trustful way on the development of the other sciences, professions and policies (Öhman, Häckner, and Sörbom, 2012).

\section{The Internal Audit Shift}

Traditionally, internal audit had focused primarily on identifying policy violations and encouraging compliance with regulations. However, internal audit activities have recently turned their focus on an integrated approach to risk management, not only as a result of the changing nature of the market and industry regulations but also in an effort to release the auditors' creativity and usefulness, upgrading their status into a trusted advisor's level (Jedrzejowicz et al., 2010). The relevant regulatory frameworks and auditors' job descriptions are being transformed so they can offer auditors and their clients sufficient leeway to establish trust (Aschauer et al., 2017). The new definition of internal auditing describes the function as an independent, objective assurance and 
consulting activity designed to add value and improve an organisation's operations. Despite the numerous differences in viewpoints and objectives, a definite shift has occurred in the overall scope of internal audit towards a more interactive and comprehensive involvement in the evaluation of the operational activities (Nagy and Cenker, 2002).

The professional range of the internal auditor's engagements is constantly being expanded. The combinations of the past and future terms depict the new orientation lines; from correction to prevention, from accounting focus to organisational added value, collaborative attitude, holistic approach, comprehensive support and insightful advisory.

\section{The EUI Library: A Long History of Innovation}

Behind the discussion on the libraries and auditing transformation this paper concentrates on the case study of EUI Library, setting the question: "why European University Institute (EUI) Internal Audit Office (IAO) and the Library could start a new way of cooperating, then exported in other EUI units?"

The European University Institute's Library joined the afore-mentioned evolution streams by early redefining early on the librarians' roles and responsibilities in such a demanding and dynamically changing context. Forty years of investment in collections, services and infrastructure, resulted in an internationally recognised social science research library, valued for its multi-national character and the high quality of its collections with a special emphasis on Europe. The Library includes a European Documentation Centre (EDC) focused on the academic research needs, manages the EUI Research Repository, Cadmus, which currently contains more than 20.000 records, and is involved in Open Access and Open Data management projects.

The strong commitment of the Library in supporting in full its doctoral and post-doctoral students resulted in a self-managed system of collecting usage data, setting performance indicators, submitting surveys, implemented far before this best practice was settled as a requirement for all EUI administrative services. Therefore, the patrimony of statistics concerning the Library activities dates already back to the ' $80 \mathrm{~s}$, as well as the practice of using this data for planning. Data is collected and organised according to SCONUL system (SCONUL, 2016). This was eventually a perfect starting point for the collaboration between the Internal Audit and the Library.

\section{EUI Management and Auditing Synergy}

The core documents of the EUI management are the Five Year Strategic Plan and the Annual Activity Report. This last report is addressed by each administrative service to the EUI top management and the Internal Audit Office (see below, Figure 1), reflecting the executive management decisions and actions.

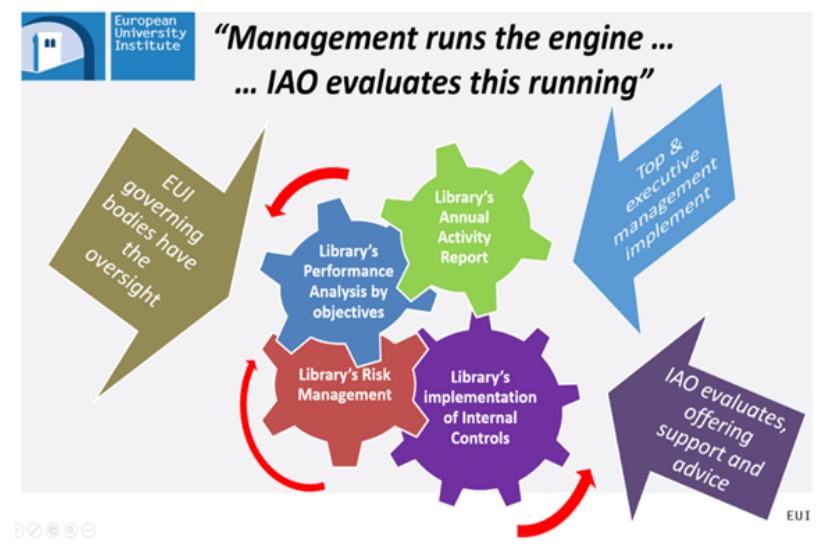

Figure 1: The mechanism supporting EUI Library's management 
In the case of the 2016 EUI Library examined, the Report explains transparently all the annual general and specific objectives and sets out the respective performance indicators (Parmenter, 2015). The results that are produced from this analysis are necessary to define and frame the EUI Library's risk assessment. The follow up risk analysis will then result in the establishment of Library's internal controls, heading in the mitigation of the non-accepted risks. In this context of periodic and cyclical interactions among objectives, performance indicators, risks and controls, the EUI governing bodies have the oversight, while the Internal Audit Office has the responsibility to evaluate and support when necessary, offering continuous consultation.

"Figure 1" refers to a "mechanism" of integrated activities and engagements, where the design of the governance system does not have a mechanistic or stagnantly bureaucratic character, but aims to recycle relevant and practical information for the stakeholders involved. Even now, several side effects of the newly re-engineered relationship between the standardised managerial services and the rise of a holistic audit culture, generate the "audit-phobia" of a possible "overdose" of assessment and accountability systems. For instance, university teaching and learning, research and academia in general should enjoy a level of autonomy and creativity not measurable in terms of core cost accounting, as happens in the stock markets. Libraries also have singularities which require a special customised treatment as well as situational understanding on behalf of managers and auditors participating in the equation of interoperability applicable in the modern education institutions (Lilburn, 2017). In the following paragraphs the case of the Library Annual Report is further illustrated.

\section{EUI Library's General and Specific Objectives}

The General Objectives of the EUI Library for 2016 were part of the overall strategy of the Library for 2016 - 2020. With five general objectives and many related specific objectives set in 2015 for the next year, the EUI Library presented a wide and far-sighted activities implementation strategy. Some of them require more than one year for their complete fulfilment. The main EUI Library General Objectives were:

1. increasing and maintaining the high quality of the library collection and services while incrementing the electronic content available remotely for a more distributed, user-oriented service;

2. providing in-site and distributed services: reshaping the Library spaces in a user-centric way;

3. implementing a new Integrated Library System (ILS) as part of the continuous technological development of the Library towards a better user experience;

4. making the EUI research output more visible and available through Open Access to the wider scholarly community;

5. developing international cooperation through the participation in various national and international associations, consortia and scholarly networks.

EUI Library objectives are related with many PIs that allow the Library's staff and the EUI top management to have an excellent overview and a self-explanatory systematic tool to monitor the progress in achieving the general and specific objectives. The analysis of the self-evaluation of one of these objectives, as an example, can clarify the method. General Objective no. 1 is broken down to two Specific Objectives. The first one, consisting in a gradual but constant move from the print model to the online model, is related to many Pls (see: Figure 2), such as: PI 1.2 Total paper volumes 566.441 (whose number is increasing, but at a lower rate in comparison to previous years), PI 1.4 and 1.18 (in decrease), as well as PI 1.19. All these Pls show a decrease in print acquisitions. On the other hand, the electronic collection is in expansion, mostly thanks to journal packages and archives (PIs 1.5; 1.20-23) and e-books purchases (PI 1.3). The second Specific Objective includes a revision of the Library Collection Policy to reflect the changing market and user needs. 


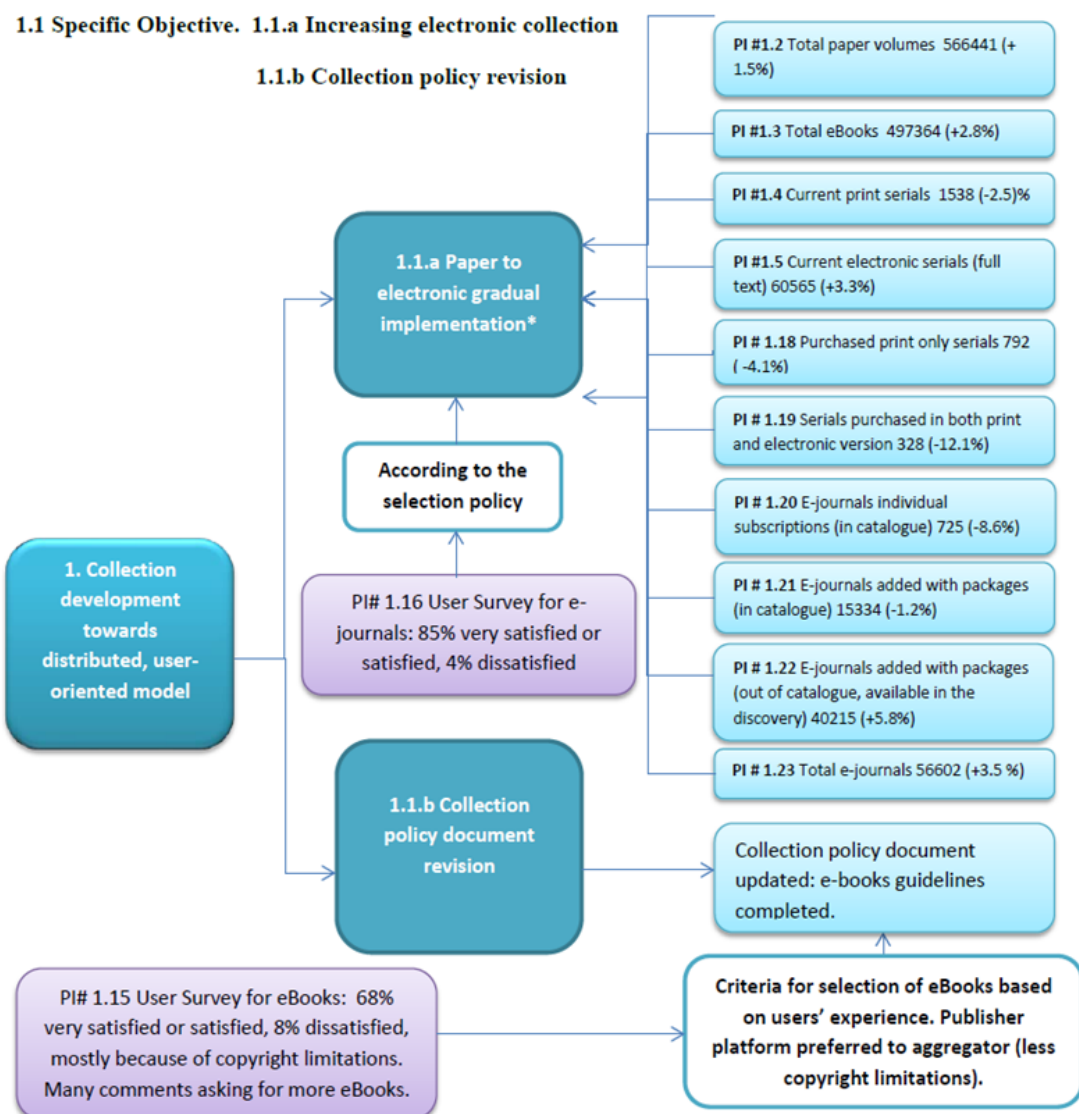

Figure 2: Specific objective of the EUI Library - Increasing electronic collection and collection policy revision

Source: Library Annual Report 2016. Percentages indicated in PIs refer to the percentage change in comparison to the previous year.

Performance indicators are used to measure, monitor and provide information on the gaps between actual and targeted performance. They can be used to determine organisational effectiveness and operational efficiency (Herrmann, 2015). They also take many forms in order to provide a wellinformed performance analysis as well as an efficient monitoring of the objectives' progress. For this reason, a combination of indicator types is often used selecting performance measures that can be gathered and tracked on an ongoing basis, while they are not too complex to be comprehended (Gupta, Sharma and Narayan, 2017). Performance indicators need to be precisely defined so that they are clear, meaningful, and measurable. This concept is effective also for identifying the risks, considered as threats to the objectives' accomplishment. The EUI Library adopted SCONUL indicators, complemented by some specific self-established indicators.

\section{Linking Objectives and PIs with Risks and Controls}

After the risk assessment, it is important to set up a risk mitigation plan that is the process of developing options, actions and mitigating controls to enhance opportunities and reduce threats to the general and specific objectives. For instance, the main EUI Library's risk was, according to the relevant Annual Report section, the "Stagnation or reduction of long-term structural EUI funding for 
the library, creating a difficulty to meet the research needs of the EUI community, thus undermining the international reputation of the EUI as a first-class European research institution". For this risk three mitigating controls were identified, such as:

- Control 1. Accurate selection applied to acquisitions of new books and serials (print and electronic) along with other savings (staff training, binding, other running expenditure).

- Control 2. Participation in national consortia negotiations with publishers, and direct negotiation, when needed, according to specific sets of requirements; thus obtaining favourable yearly price caps, abundance of content, better licence terms for users.

- Control 3. Yearly revision and evaluation of the whole periodicals and electronic resources collections on a title by title basis (Alpigiano and Daalder, 2016).

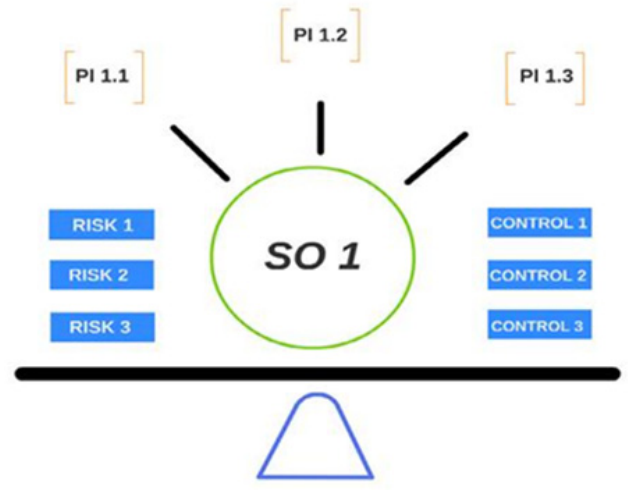

Figure 3: The example of how a specific EUI Library objective is framed by performance, risk and control analyses towards its achievement

The mitigating controls are, of course, fundamental and critically important for all the risk analysis and for the achievement of the general and specific objectives. The risk manager is responsible for identifying and implementing the risk mitigation plan. This role requires knowledge, authority, and resources to implement the plan (Gibson, 2014). Risk mitigation controls are effective to minimise the impact or the likelihood of the identified risk. If the risks, the Pls and the mitigating controls are well identified and implemented in interaction, it will be easier and more likely to reach the annual objectives (see above, Figure 3).

\section{Managerial Self-Assessment Implications}

In a broader view, the synergy between EUI Services and IAO has been extensively accepted and applied in the Institute's operations. This synergy aims at emphasizing the auditors' intention to comprehend the EUI Services' particularities, enhancing as much as possible their capabilities to self-assess their prospects and opportunities, averting threats and failures. The common ground where the EUI Services and IAO are met is being placed upon an integrated methodology linking objectives, risks, performance indicators and controls, customised for the EUl's administrative and operational needs. It is a little like the famous Chinese proverb: "... give a man a fish, and you feed him for a day ... teach a man to fish, and you feed him for a lifetime ..." (The Hunger Project, 2007); where the auditors are called on not to blame in the aftermath of the administrative difficulties, but instead to provide in advance the know-how of a systematic self-assessment and timely prevention of irregularities (Bamberger, 2010).

In general, a critical source of the auditing changes in discussion was that the international standards on auditors' responsibilities have lately placed the primary responsibility for corporate accountability on management, along with the need for adequate internal control systems and the interpretation of compliance as a prevention system. Internal audit engagement and support is 
being consequently expressed by supporting management in defining internal control procedures, improving communication channels between internal auditors and management (Rittenberg, 1980). Going in this direction, an example demonstrating such a collaborative and non-intrusive spirit (see below, Figure 4) and practice among the modern auditing trends is the so called concept of "Continuous Auditing" (Weins, Alm, and Wang, 2016).

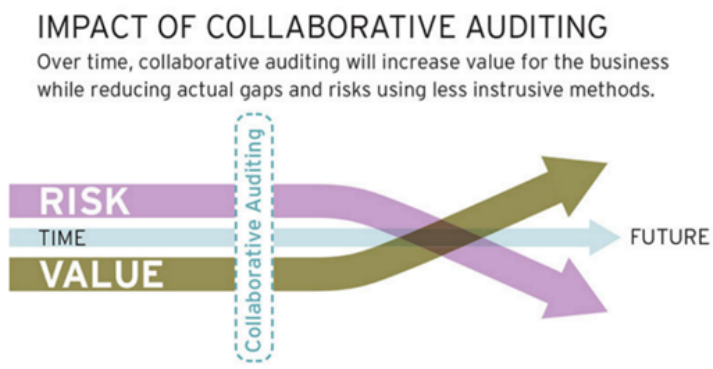

Figure 4: The added value of a collaborative and non-intrusive impact auditing (D'Cunha, 2013).

\section{Conclusions}

Cooperation in the methodological context described above among several EUI administrative services, such as the Library and the Internal Audit Office, results in remarkable organisational benefits. EUI management may reasonably ensure a coherent and streamlined workflow which is characterised by the fact that the objectives defined are concrete and achievable, risks are taken into account and prioritised, while the progress of the objectives' achievement is being monitored, justified and updated with a S.M.A.R.T. approach, i.e. on the basis of specific, measurable, timely updated and relevant data (Dlabay, Burrow, and Kleindl, 2016).

In general, the evolution of organisational behaviour and administration has massively turned to technology systems and computational analytics that measure the performance and predict risk levels driving to respective decision making (Bamberger, 2010). The regulators have welcomed the move to technology, but there are always present and usually ignored perils, accountability challenges posed by the technologies of control, therefore both managers and auditors should be alerted recommending reform measures and revisiting the governance of risk.

The underlying philosophy of the Self-Assessment based management has profoundly positive implications especially for the Libraries' governance: auditors may facilitate the Libraries managers' empowerment through supporting their assessment capabilities and risk-based decision making. The model works metaphorically like a "medical self-diagnostic" system where the managers identify and mitigate their weaknesses long before they suffer organisational "health" problems and need an extended remedial treatment (Alles, Kogan, and Vasarhelyi, 2008). The development of an integrated and continuous auditing approach is an ambitious auditing vision that is highly expected to recover the troubled relationship between managers and auditors by cultivating mutual understanding and collaboration towards the common objectives of institutions and organisations.

\section{Acknowledgements}

Authors would like to express their gratitude to Mr. Leonardo Doni and Mr. Janis Balodis for their outstanding contribution to the research supporting this publication.

\section{References}

Alles, M. G., Kogan, A and Vasarhelyi, M. A., (2008). Putting Continuous Auditing Theory into Practice: Lessons from Two Pilot Implementations, Journal of Information Systems, Vol. 2, No. 22, 195-214. 
Alpigiano, C. and Daalder, M., (2015). The bright side of procedures in a period of crisis: acquisitions decisionmaking at the EUI Library, Qualitative and Quantitative Methods in Libraries (QQML), Vol. 4, No. 2, 659 -66.

Armstrong, K., Keating, N. L., Landry, M., Crotty, B. H., Phillips, R. S. and Selker, H. P., (2013). Academic General Internal Medicine: A Mission for the Future, Journal of General Internal Medicine, Vol. 6, No. 28, 845-51.

Aschauer, E., Fink, M., Moro, A., Van Bakel-Auer, K. and Bent Warming - Rasmussen, B., (2017). Trust and Professional Skepticism in the Relationship between Auditors and Clients: Overcoming the Dichotomy Myth, Behavioral Research in Accounting, Vol. 1 No. 29 (1), 19-42.

Baltos, G, C., Ioannis G. Vidakis, I, G., (2014). Quality Management - ISO Quality Standards. Auditing applications in Private and Public Sector. Stamoulis Publications, Athens.

Bamberger, K. A., (2010). Technologies of Compliance: Risk and Regulation in a Digital Age, Texas Law Review, Vol. 4, No. 88, 669-739.

Caruthers, R. A., (2011). Effective leadership in a 21st - century federal agency. D.B.A., Baker College (Michigan), Ann Arbor.

D'Cunha, R., (2013). A Collaborative Check-up, Internal Auditor, Vol. 70, No. 2, 62.

Dempsey, L., (2017). Library collections in the life of the user: two directions, Liber Quarterly, Vol. 26, No. 4, 338-359.

Dlabay, L., Burrow, J. L. and Kleindl, B., (2016). Principles of Business: Cengage Learning, Mason.

Gibson, D., (2014). Managing Risk in Information Systems: Jones \& Bartlett Learning, LLC.

Grover, I, A., (2012). Can Leaders Influence a Learning Organization? An Exploratory Study of the Relationship between Leadership, Organizational Learning Capability and the Mediating Role of Trust. M.Sc., University of Ottawa (Canada), Ann Arbor.

Henricks, S. A. and Henricks-Lepp, G. M., (2014). Desired Characteristics of Management and Leadership for Public Library Directors as Expressed in Job Advertisements, Journal of Library Administration, Vol. 4, No. 54, 277-290.

Herrmann, J. W., (2015). Engineering Decision Making and Risk Management: Wiley.

Hoidn, S., (2016). Student-Centered Learning Environments in Higher Education Classrooms: Palgrave Macmillan US.

The Hunger Project., (2007). Why We Don't Teach People to Fish. Rothschild Design, New York.

Jedrzejowicz, P., Nguyen, N. T., Howlett, R. J. and Jain, L. C. (2010): Agent and Multi-Agent Systems: Technologies and Applications. Proceedings of the 4th KES International Symposium, KES-AMSTA 2010, Gdynia, Poland, Springer-Verrlag.

Lakhe, R. R. and Mohanty. R. P., (1994). Total quality management - Concepts, evolution, and acceptability in developing economies, The International Journal of Quality \& Reliability Management, Vol. 9, No. 11, 9.

Leek, J, W., (1987). The Issues in Quality: Quality's Evolution in the US. Quality: 3.

Lilburn, J., (2017). Ideology and Audit Culture: Standardized Service Quality Surveys in Academic Libraries, Portal : Libraries and the Academy, Vol. 1, No. 17, 91-110.

Meredith, J, R., (2009). Issues in The Modeling - Empiricism GAP, Journal of Supply Chain Management, Vol. 1, No. 45, 44 - 48.

Nagy, A. L. and Cenker, W. J., (2002). An assessment of the newly defined internal audit function, Managerial Auditing Journal, Vol. 3, No. 17, 130-137.

Nicholas, P., Sterling, J., Davis, R., Lewis, J, C., Mckoy-Johnson, F., Nelson, K., Tugwell, Y. and Tyrell, K., (2015). Bringing the Library to You!, New Library World, Vol. 116, No. 5, 316-335.

Norris, C. A. and Soloway, E., (2011). Learning and Schooling in the Age of Mobilism, Educational Technology, Vol. 6, No. 51, 3-10.

Öhman, P., Häckner, E. and Sörbom, D. (2012). Client satisfaction and usefulness to external stakeholders from an audit client perspective, Managerial Auditing Journal, Vol. 5, No. 27, 477-499.

Parmenter, D. (2015): Key Performance Indicators: Developing, Implementing, and Using Winning KPIs: Wiley.

Raja, S., Memoona, H., Vadakumchery, T., Hamad, J., Shah, R. and Hoersch, M., (2015). Identifying Elements of Patient-Centered Care in Underserved Populations: A Qualitative Study of Patient Perspectives, PLoS One, Vol. 5, No. 10. Rittenberg, L. E., (1980). Expanding Opportunities for Internal Audit Service, The Internal Auditor, Vol. 2, No. 37, 73.

Roco, M. C. and Bainbridge, W. S., (2013). The new world of discovery, invention, and innovation: convergence of knowledge, technology, and society, Journal of Nanoparticle Researc, Vol. 9, No. 15, 1-17.

Russell, J. P. and A.S.Q.Q.A. Division. (2012). The ASQ Auditing Handbook, Fourth Edition: ASQ Quality Press. SCONUL (2016), SCONUL Annual Statistics, 2014-15, SCONUL, London.

Weins, S., Alm, B. and Wang, T., (2016): Rethinking The Future of Auditing: How an Integrated Continuous Auditing Approach Can Leverage the Full Potential of Continuous Auditing. ZBW - German National Library of Economics. 